interaction which were dealt with in the first volume. Division of the contributions into four sections - biosynthesis, gene arrangement, suppression and coding, and "other roles of tRNA" - is perhaps the best in the circumstances. However, the organization and expression of tRNA genes are so intimately linked that articles in the first two sections overlap and some of them also impinge upon suppression which has proved such a useful property in study of tRNA transcription and processing.

The opening section on tRNA biosynthesis begins, as do most sections in both volumes, with a useful general review of the topic by the session chairman at the meeting. There then follow a dozen shorter articles in which specific genetic and enzymological studies are thoroughly covered. Gene arrangement is introduced by a beautifully succinct review. The topics of the articles that follow, though broadranging, are somewhat unbalanced with four articles on Drosophila, including three on in situ hybridization, but none on tRNA genes in mitochondria or in Xenopus. No general reviews introduce the final two sections of the book. While a brief overview of the rather esoteric topic of suppression would have been most useful, the diverse topics of the final section could only be dealt with satisfactorily by individual articles. The volume concludes with three appendices on tRNA gene localization and codon usage.

One final comment should be made on the two-year delay in publication which, in some respects, is fortunate rather than regrettable. In mid-1978 there were tantalizing promises of rapid advance in some of the newer fields of study, such as tRNA gene organization in eukaryotes and removal of intervening sequences from tRNA precursors. The contributors have made an admirable job of updating their articles - of the 1300 references cited, nearly 200 date from 1978, 75 from 1979 and 16 from 1980 . Thus most of the discoveries in the year following the 1978 meeting are reported in this volume.

The book has all the qualities one has come to expect from Cold Spring Harbor monographs and should find an appreciative readership among workers in tRNA research and in molecular biology generally.

J.P. Goddard is a Lecturer in Biochemistry at the University of Glasgow.

\title{
Epithelial physiology: tribute to Jean Maetz
}

\section{Clive Ellory}

Epithelial Transport in the Lower Vertebrates. Edited by B. Lahlou. Pp.366. (Cambridge University Press: 1980.) £25, \$55.

THIS book represents a memorial symposium held as a tribute to Jean Maetz by many of his friends, colleagues and collaborators. It was a meeting Jean would certainly have enjoyed, the emphasis being on fish and amphibian epithelial physiology, with many authors concentrating on endocrinological aspects. Aside from the obvious environmental attractions of working in Villefranche, Naples or Woods Hole, physiologists have become increasingly interested in fishes for studying the mechanisms of epithelial secretion. Fish gills and opercular skin, flounder intestine and shark rectal gland are all preparations which have generated valuable models and influenced thinking on epithelial function. These systems exercised Jean Maetz's considerable talents and represent the principal content of the present volume.

Papers on fish gills comprise half the total contributions. Thus, gill structure and function are covered well in the initial section, with emphasis on vasculature and functional morphology. The importance of the chloride cell in gill physiology is apparent from the number of times this topic recurs in the book, and from the descriptions of the exciting, isolated skin preparations from Fundulus and
Gillichthys. New results, including data on gill permeability to large molecules, and some detailed electron microscopy produce tentative functional models for the chloride cell. Other gill transport systems beside $\mathrm{Cl}$ covered in the book include $\mathrm{Na}^{+} / \mathrm{NH}_{4}$ exchange and calcium transport. There are good biochemical presentations on gill $\mathrm{Na}, \mathrm{K}-\mathrm{ATP}$ ase and the more controversial anion-stimulated ATPase. A salutary lesson is presented in the Na,K-ATPase chapter, where vanadate, a specific inhibitor of this enzyme in vitro, was found to be functioning on gills in vivo as a vasoconstrictor.

Kidney is mostly approached from an endocrinological point of view, although there are two impressive studies on single nephron physiology which emphasize the widely different roles for the kidney in marine and freshwater fish. Intestinal functions discussed include salt and amino acid transport, and amphibian skin is represented by three contributions mostly concerned with epithelial sodium transport. Endocrinological factors are emphasized in many of the contributions, but there are two small reviews dealing specifically with the hormonal control of ion transport.

Overall, there is much of interest in this book. Selection criteria for participants in such a memorial symposium obviously include factors which are not strictly scientific or rigorously thematic, which is reflected by some unevenness, with certain elements sitting less easily under the general title. There are also clear differences in scientific content, philosophy and merit among the various contributions, including some which are trivial or frankly eccentric. However, on balance this is a fitting tribute to Jean Maetz, which should prove valuable to fish physiologists and epithelial transport workers.

Clive Ellory is a Lecturer in Physiology at the University of Cambridge.

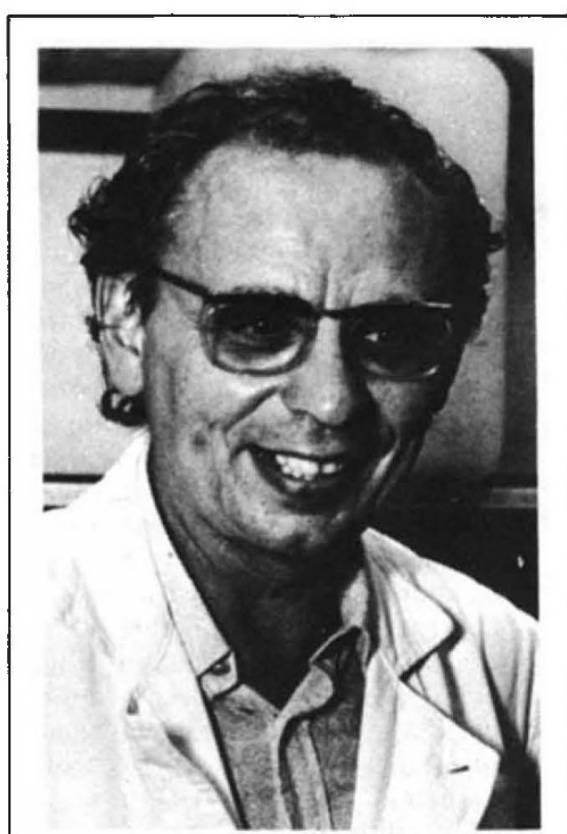

Jean Maetz , a talented physiologist

\section{Birds in brief}

\section{Robert Hudson}

A Complete Checklist of the Birds of the World. By Richard Howard and Alick Moore. Pp.701. (Oxford University Press: 1980.) £17.50, \$49.50.

THIS book comprises a straightforward listing of the living birds of the world, giving for each species the scientific and selected English name and a brief indication of geographical range; for polytypic species, named subspecies are also listed. Essentially, it is a condensed and partly updated version of the authoritative 15-volume Checklist of the Birds of the World edited by J.L. Peters and others (Harvard University Press, 1931-1979), but lacking the taxonomic and nomenclaturial comments, references and detailed distribution notes to be found in the larger work. The introduction to the present book suggests its major use will be as a handy personal checklist for the 